\title{
Estrogen, not intrinsic aging, is the major regulator of delayed human wound healing in the elderly Matthew J Hardman and Gillian S Ashcroft
}

Address: Faculty of Life Sciences, University of Manchester, Oxford Road, Manchester M13 9PT, UK.

Correspondence: Matthew J Hardman. Email: matthew.j.hardman@manchester.ac.uk. Gillian S Ashcroft. Email: gillian.s.ashcroft@manchester.ac.uk

Published: 13 May 2008

Genome Biology 2008, 9:R80 (doi:10.1186/gb-2008-9-5-r80)

The electronic version of this article is the complete one and can be found online at http://genomebiology.com/2008/9/5/R80
Received: 4 April 2008

Revised: 7 April 2008

Accepted: 13 May 2008

(C) 2008 Hardman and Ashcroft; licensee BioMed Central Ltd.

This is an open access article distributed under the terms of the Creative Commons Attribution License (http://creativecommons.org/licenses/by/2.0), which permits unrestricted use, distribution, and reproduction in any medium, provided the original work is properly cited.

\begin{abstract}
Background: Multiple processes have been implicated in age-related delayed healing, including altered gene expression, intrinsic cellular changes, and changes in extracellular milieu (including hormones). To date, little attempt has been made to assess the relative contribution of each of these processes to a human aging phenomenon. The objective of this study is to determine the contribution of estrogen versus aging in age-associated delayed human wound healing.

Results: Using an Affymetrix microarray-based approach we show that the differences in gene expression between male elderly and young human wounds are almost exclusively estrogen regulated. Expression of 78 probe sets was significantly decreased and 10 probe sets increased in wounds from elderly subjects (with a fold change greater than 7 ). A total of $83 \%$ of down-regulated probe sets and $80 \%$ of up-regulated probe sets were estrogen-regulated. Differentially regulated genes were validated at the level of gene and protein expression, with genes identified as estrogenregulated in human confirmed as estrogen-dependent in young estrogen depleted mice in vivo. Moreover, direct estrogen regulation is demonstrated for three array-identified genes, Sele, Lypd3 and $\mathrm{Arg} I$, in mouse cells in vitro.

Conclusion: These findings have clear implications for our understanding of age-associated cellular changes in the context of wound healing, the latter acting as a paradigm for other agerelated repair and maintenance processes, and suggest estrogen has a more profound influence on aging than previously thought.
\end{abstract}

\section{Background}

In elderly subjects wound healing is severely impaired, accompanied by substantial morbidity, mortality and an estimated cost to health services of over $\$ 15$ billion per annum in the US alone. A unified theory of biological aging is emerging in which cellular maintenance and repair systems are influenced by genes and environment, and wound healing is one of the main pathways of such repair responses [1]. Hormones are potential determining factors in the aging process, and estrogen has been shown to be beneficial in accelerating the age-related impaired tissue repair response in the skin of both genders $[2,3]$. Elderly male subjects have the highest incidence of chronic non-healing wounds [4,5], correlating with reduced local levels of the beneficial hormone estrogen, with 
relative maintenance of the androgen hormones that are detrimental to healing [6]. Thus, estrogen has been viewed as a piece of the complex jigsaw modulating aging repair processes. Multiple processes have been implicated in cutaneous aging, including gene expression, intrinsic cellular change and an altered extracellular milieu. However, the relative contribution of each of these processes to age-associated delayed healing is unknown. Here at the level of gene expression, we provide novel insight into the relative contribution of hormones and intrinsic aging, including gerontogenes, to delayed wound healing.

There exists a substantial body of research addressing the tissue, cellular and molecular changes that accompany or directly contribute to aging in a range of model organisms (reviewed in [7]). However, the majority of data, generated in model organisms or in vitro (cellular senescence), has yet to be validated in human aging. Moreover the relative contribution of putative gerontogenes to human pathological agerelated processes is unknown. Age-associated impaired healing correlates with increased inflammation, increased matrix proteolysis and delayed re-epithelialization leading to chronic wound states, processes modulated by exogenous estrogen treatment [8]. In a recent study we characterized estrogen-regulated changes in gene expression using a model of delayed wound healing in young mice that have been rendered hypogonadal by ovariectomization (hence removing any effects of 'intrinsic aging') [9]. Thus, using comparative analysis we are now in a position to address the relative contributions of estrogen and aging to healing in elderly humans.

Since the major variable contributing to chronic wounds in humans is being an aged male [4,5], our initial approach was to compare acute wound gene expression between young and old male human subjects via Affymetrix microarray. We used the principle of data mining for gene enrichment [10] followed by a cross-species comparison to our recently published dataset of mouse wound estrogen-regulated genes [9] and interrogation of the Dragon online database of estrogenregulated genes [11] combined with manual annotation to identify estrogen regulated probe sets. Androgen levels, which inhibit healing, are relatively well-maintained in elderly males (data not shown), thus the potential effects are cancelled out when comparing males of different ages. Putative-gerontogenes and genes with established aging-related functions were identified by interrogation of the GenAge online database [12], from aging-associated Gene Ontology (GO) groups and from hand annotation (see Materials and methods/Results for a detailed description of the analysis). We show that the fundamental changes in genes and processes linked to the pathophysiology of age-related delayed healing in humans appear to be almost exclusively estrogen regulated. Estrogen exerts its effects by down-regulating a variety of genes associated with regeneration, matrix production, protease inhibition and epidermal function and up-regulating genes primarily associated with inflammation. These findings have clear implications for our understanding of ageassociated cellular changes in the context of wound healing, and are highly relevant with respect to many other agerelated repair and maintenance processes.

\section{Results and discussion}

We initially used immunohistochemical analysis to determine and compare the temporal profile of cellular change in wounds from young and elderly males (Figure 1). We observed clear age-dependent differences in wound numbers of inflammatory cells (neutrophils and macrophages) and rate of re-epithelialization early in healing (three days postwounding; D3) and fibroblasts/blood vessels during the tissue remodeling phase (three months post-wounding; 3Mo). Crucially, we identified seven days post-wounding (D7) as a period where in males wound cellular composition is equivalent in both young and elderly subjects. This finding facilitated subsequent microarray analysis of wound gene expression by eliminating the possibility of changes in gene expression arising due to disproportionate representation of a specific cell type between biological samples. Hence, changes identified are the result of actual changes in wound gene expression.

For the purpose of this study, probe sets showing significant differential regulation between young and old human wounds were identified by filtering for a fold change of \pm 7 -fold, a qvalue $<0.1$ and expression level $>15$ (see Additional data file 1 for the full list of identified probe sets; 10 up-regulated and 78 down-regulated). We then used a combination of sources to identify estrogen-regulated genes. We exploited the Dragon online database [11] to assemble a subset of estrogen-regulated genes (subset S1; Additional data file 2). We re-analyzed our own recently published mouse estrogen-regulated gene data set [9] (see Materials and methods) and through comparative analysis identified a gene subset conserved between human and mouse (subset S2; Additional data file 3). A third subset was compiled through hand annotation (subset S3; Additional data file 4). The vast majority of differentially expressed genes were estrogen-regulated (Table 1, Figure 2) and most were down-regulated in wounds from elderly subjects. Using a binomial distribution calculation we determined that our enriched data set contained many more estrogen-regulated genes than would be expected to arise by chance (Dragon: observed $=20$, expected $=9.3, p=0.0002$; and Mouse data set: observed $=19$, expected $=3.8, p=0.0$ ).

Down-regulated estrogen-regulated genes were highly enriched for epidermal GO groups, such as epidermal development (EASE $p=2.7 \mathrm{E}-16$; Figure 2; Additional data file 5). We observed a strong reduction in epidermal differentiationassociated genes, particularly those encoding cornified envelope proteins (8 genes; EASE $p=0.00027$ ), such as $L O R$ (235-fold reduction) and FLG (114-fold reduction), suggesting a delay in barrier formation. Within hours of injury 


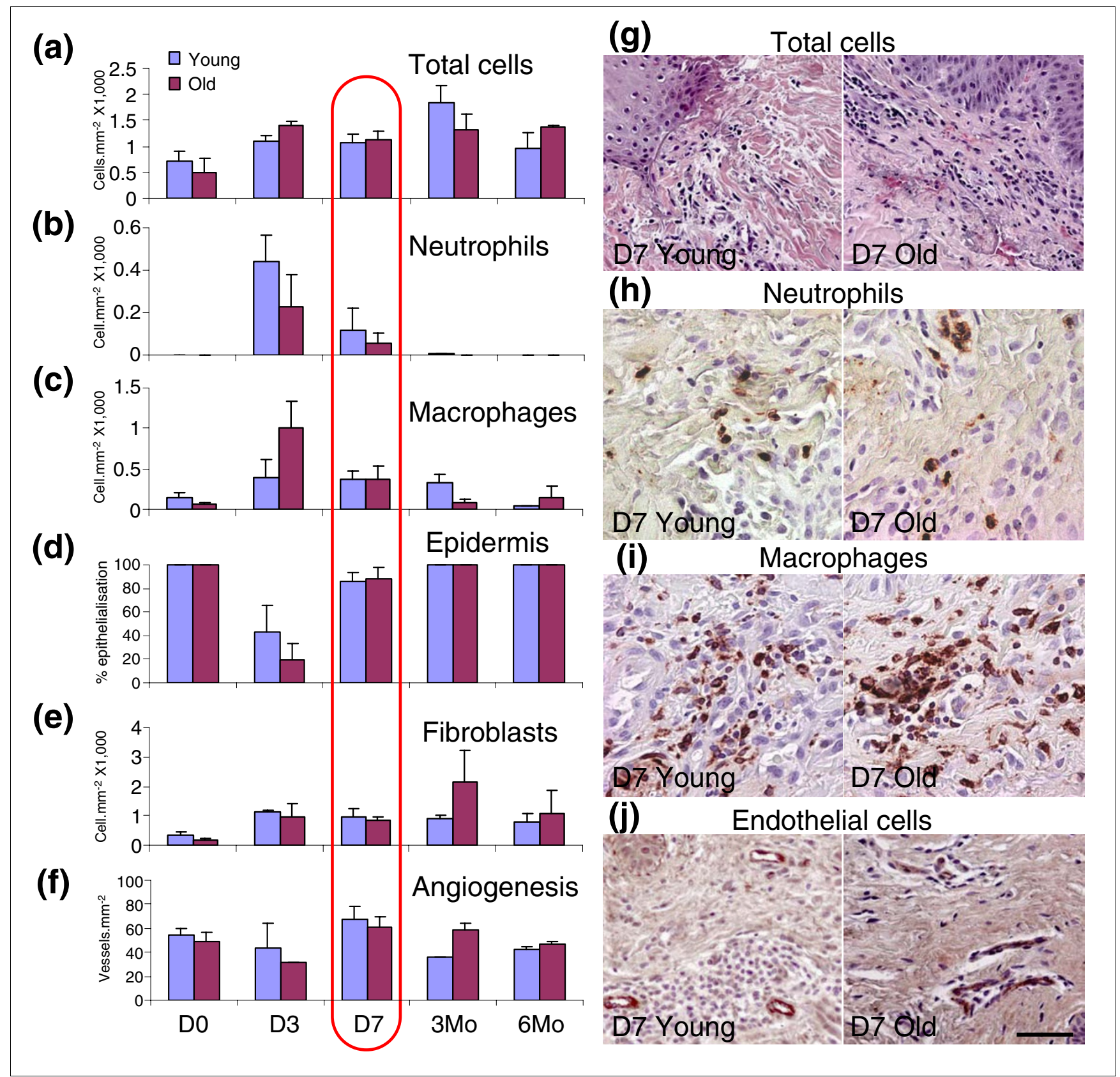

Figure I

Temporal profile of changes in wound cellular composition. (a) Total granulation tissue cell numbers increase over time with no difference between young and old male subjects prior to three months. Closer examination reveals that the inflammatory cell profiles for (b) neutrophils and (c) macrophages differ significantly at day 3 (D3) post-wounding. (d) Differential re-epithelialization is also apparent at this time-point (D3). (e,f) In contrast, fibroblast and blood vessel numbers are increased in wounds from elderly subjects at the three month (3Mo) time point. Note equivalent numbers of each cell type in young and old wounds at D7 (red highlight), the time-point chosen for this study. (g-j) Comparative images for total cell (hematoxylin and eosin; g), neutrophil (CDI5; h) macrophage (CD68; i) and endothelial cell (VWF; j) immunostaining. The scale bar in (j) represents $50 \mu \mathrm{m}$ (g), $20 \mu \mathrm{m}$ (h), $35 \mu \mathrm{m}$ (i), and $45 \mu \mathrm{m}$ (j).

epithelial cells are mobilized to restore tissue functional integrity. Multiple genes associated with these specific processes are strongly down-regulated in wounds from elderly subjects (Table 1). These include the hyperproliferation-associated keratin, KRT16 (8.3-fold reduction) and LYPD3 (9.7fold reduction), a uPAR homologue that is up-regulated in migrating keratinocytes. These findings correlate with the observation that aged keratinocytes show a depressed migratory capacity compared to young cells in a wound environment [13]. Indeed, in wounds from both elderly humans and ovariectomised (ovx) mice re-epithelialization is attenuated (Figure 1) $[2,14]$ and can be restored by topical or systemic 
Table I

\begin{tabular}{|c|c|c|c|c|c|}
\hline Affy ID & Gene* & Gene (description) & Function & q-value ${ }^{\dagger}$ & $\mathrm{FC} \ddagger$ \\
\hline \multicolumn{6}{|c|}{ Down-regulated probe sets (65) } \\
\hline 207720_at & LOR & loricrin & Major cornified envelope protein & 0 & -235 \\
\hline 201909_at & RPS4YI & ribosomal protein S4, Y-linked I & $40 \mathrm{~S}$ ribosomal component & 0 & -142 \\
\hline 215704_at & FLG & filaggrin & Cornified envelope-keratin linker & $9.4 \mathrm{E}-13$ & -114 \\
\hline 206177_s_at & ARGI & arginase, liver & Delayed healing-associated & $9.2 \mathrm{E}-\mathrm{II}$ & -82.0 \\
\hline 206643_at & $H A L$ & histidine ammonia-lyase & Histidine catabolism & $1.5 \mathrm{E}-10$ & -59.0 \\
\hline 20642I_s_at & SERPINB7 & $\begin{array}{l}\text { serpin peptidase inhibitor, clade B } \\
\text { (ovalbumin), member } 7\end{array}$ & Proteinase inhibitor for plasmin & $5.9 \mathrm{E}-13$ & -47.6 \\
\hline 206192_at & CDSN & Corneodesmosin & Desquamation/adhesion & $2.5 \mathrm{E}-06$ & -30.1 \\
\hline 213796_at & SPRRIA & small proline-rich protein IA & $\begin{array}{l}\text { Cornified envelope precursor } \\
\text { protein }\end{array}$ & $1.5 \mathrm{E}-05$ & -29.4 \\
\hline 207324_s_at & DSCI & desmocollin I & Desmosomal cadherin/adhesion & $9.6 \mathrm{E}-06$ & -28.9 \\
\hline 209719_x_at & SERPINB3 & $\begin{array}{l}\text { serpin peptidase inhibitor, clade B } \\
\text { (ovalbumin), member } 3\end{array}$ & Inflammation and cancer-associated & I.6E-05 & -22.4 \\
\hline 217496_s_at & IDE & insulin-degrading enzyme & $\begin{array}{l}\text { Wound fluid/resolution of insulin } \\
\text { response }\end{array}$ & 4.0E-06 & -20.5 \\
\hline 211597_s_at & HOP & homeodomain-only protein & Serum response factor binding & I.7E-04 & -19.7 \\
\hline 211726_s_at & FMO2 & $\begin{array}{l}\text { flavin containing monooxygenase } 2 \\
\text { (non-functional) }\end{array}$ & Non-functional oxidative enzyme & 7.0E-04 & -18.9 \\
\hline 2204|4_at & CALML5 & calmodulin-like 5 & Epidermal-associated calcium-binding & $2.0 \mathrm{E}-05$ & -17.7 \\
\hline 203328_x_at & IDE & insulin-degrading enzyme & $\begin{array}{l}\text { Wound fluid/resolution of insulin } \\
\text { response }\end{array}$ & I.4E-05 & -17.4 \\
\hline 210413_x_at & SERPINB4 & $\begin{array}{l}\text { serpin peptidase inhibitor, clade B } \\
\text { (ovalbumin), member } 4\end{array}$ & Cancer and inflammation-associated & 3.IE-05 & -15.8 \\
\hline 219795_at & SLC6AI 4 & $\begin{array}{l}\text { solute carrier family } 6 \text { (amino acid } \\
\text { transporter), member } 14\end{array}$ & Amino acid transport/obesity & $6.9 \mathrm{E}-04$ & -15.6 \\
\hline 210074_at & CTSL2 & cathepsin L2 & Lysosomal cysteine proteinase & $3.8 \mathrm{E}-05$ & -15.5 \\
\hline 222242_s_at & KLK5 & kallikrein 5 & $\begin{array}{l}\text { Desquamation, angiogenesis and } \\
\text { cancer }\end{array}$ & 4.0E-05 & -15.0 \\
\hline 201348_at & GPX3 & glutathione peroxidase 3 (plasma) & Protection from oxidative damage & I.2E-05 & -14.8 \\
\hline 202018_s_at & LTF & lactotransferrin & $\begin{array}{l}\text { Inflammatory-cell-derived } \\
\text { antioxidant }\end{array}$ & 4.6E-02 & -14.5 \\
\hline 205185_at & SPINK5 & $\begin{array}{l}\text { serine peptidase inhibitor, Kazal type } \\
5\end{array}$ & Anti-inflammatory/anti-microbial & $3.8 \mathrm{E}-05$ & -14.4 \\
\hline 211906_s_at & SERPINB4 & $\begin{array}{l}\text { serpin peptidase inhibitor, clade B } \\
\text { (ovalbumin), member } 4\end{array}$ & Cancer and inflammation-associated & 5.7E-05 & -12.4 \\
\hline 219232_s_at & EGLN3 & egl nine homolog 3 (C. elegans) & Hypoxia-inducible apoptosis-inducing & $1.4 \mathrm{E}-05$ & -12.1 \\
\hline 213256_at & MARCH3 & $\begin{array}{l}\text { membrane-associated ring finger } \\
(\mathrm{C} 3 \mathrm{HC} 4) 3\end{array}$ & Poorly characterized ubiquitin ligase & I.6E-05 & -12.1 \\
\hline 204733_at & $K L K 6$ & kallikrein 6 (neurosin, zyme) & Hormone regulated serine protease & I.4E-05 & -11.9 \\
\hline 202179_at & $B L M H$ & bleomycin hydrolase & Cysteine peptidase & 2.IE-03 & -11.8 \\
\hline 214549_x_at & SPRRIA & small proline-rich protein IA & $\begin{array}{l}\text { Cornified envelope precursor } \\
\text { protein }\end{array}$ & I.6E-04 & -11.3 \\
\hline 207908_at & KRT2 & $\begin{array}{l}\text { keratin } 2 \text { (epidermal ichthyosis } \\
\text { bullosa of Siemens) }\end{array}$ & Supra-basally expressed cytokeratin & I.2E-03 & -11.1 \\
\hline 210338_s_at & HSPA8 & heat shock $70 \mathrm{kDa}$ protein 8 & ERalpha-inhibiting heat shock protein & $9.9 \mathrm{E}-04$ & -10.6 \\
\hline 209720_s_at & SERPINB3 & $\begin{array}{l}\text { serpin peptidase inhibitor, clade B } \\
\text { (ovalbumin), member } 3\end{array}$ & Inflammation and cancer-associated & 3.3E-04 & -10.5 \\
\hline 201849_at & BNIP3 & $\begin{array}{l}\mathrm{BCL} \text { /adenovirus EIB } 19 \mathrm{kDa} \\
\text { interacting protein } 3\end{array}$ & Mitochondrial apoptosis-inducing & 2.7E-04 & -10.1 \\
\hline 205916_at & SIOOA7 & SI00 calcium binding protein A7 & $\begin{array}{l}\text { Chemotactic psoriasis-associated } \\
\text { protein }\end{array}$ & I.7E-04 & -10.0 \\
\hline
\end{tabular}


Table I (Continued)

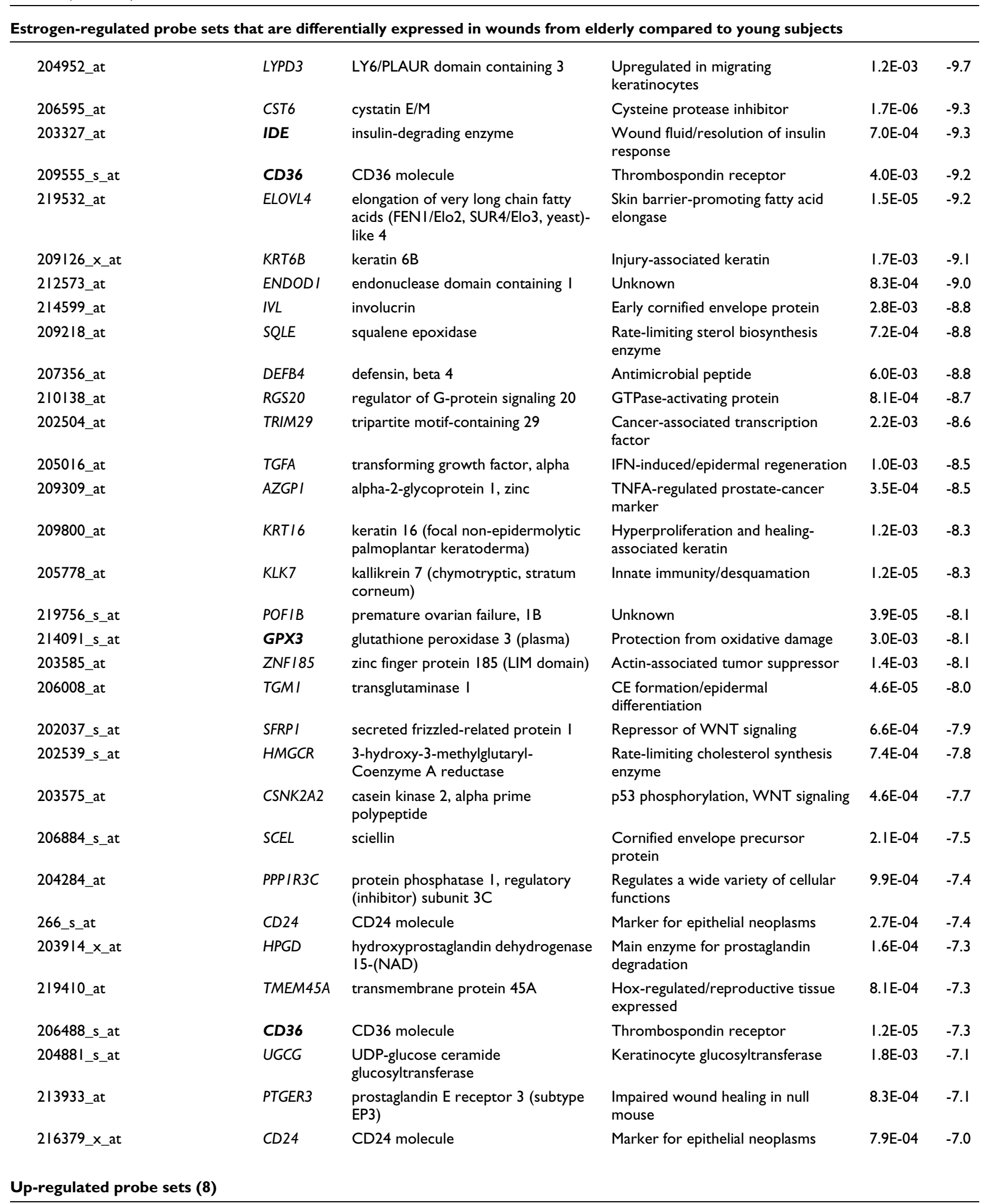


Table I (Continued)

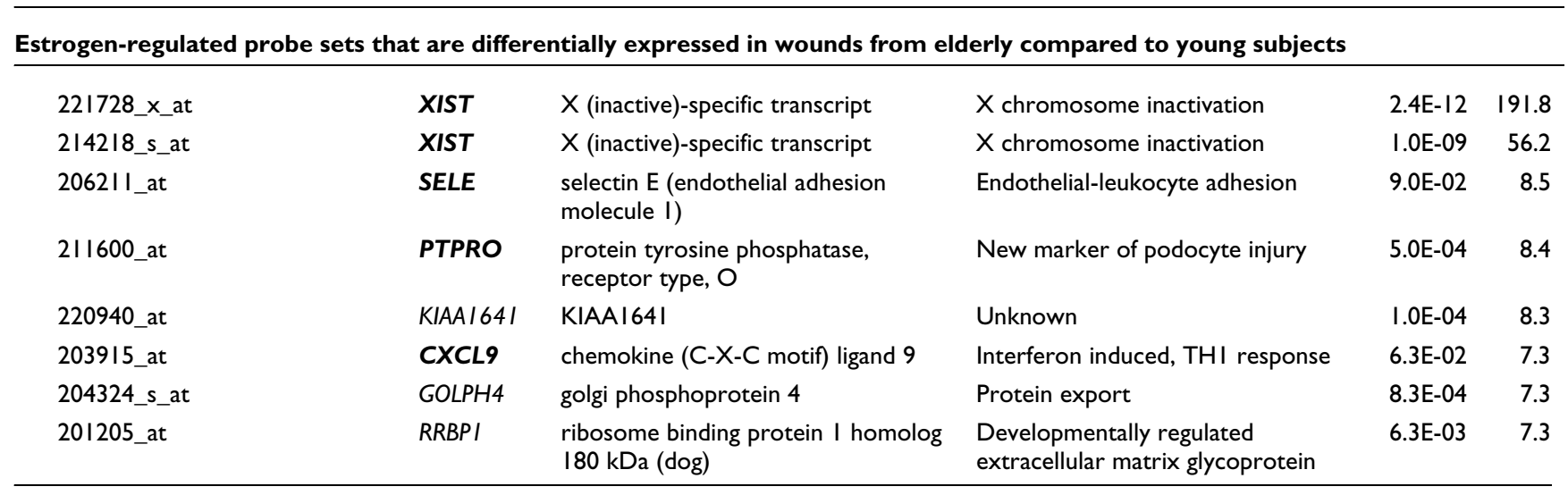

*Genes in bold have been validated by qPCR. †CyberT-derived multiple testing corrected q-value. 䇇old change (old/young).

estrogen $[2,3]$. Our data uniquely identify novel gene targets involved in this process.

It has been suggested that delayed wound healing in the elderly results from an imbalance between wound proteases and protease inhibitors, the net result of which is tissue breakdown [8]. Here we demonstrate coordinate changes in expression of estrogen-regulated protease inhibitor encoding genes, including members of the SERPIN family (six probe sets) and cystatin E/M (CST6), which act to protect against inappropriate activation of cathepsins. This suggests that delayed-healing wounds are in a profound state of protease inhibitor deprivation (EASE $p=0.0038$ ). Novel wound healing genes with dramatic fold differences include SERPINB7, which is 47 -fold down-regulated in wounds from elderly subjects, and has only previously been reported in the kidney associated with extracellular matrix overexpression [15], and SERPINB4 (17-fold down-regulated), the expression of which has, to our knowledge, never been reported in the skin. Skin expression of these novel SERPIN genes is supported by a very high number of skin-derived expressed sequence tags. In this regard, a number of anti-inflammatory, anti-oxidant, and/or anti-microbial genes are also down-regulated in wounds from elderly subjects, such as the antimicrobial peptide defensin beta 4 (DEFB4; 8.8-fold), lactoferrin ( $L T F ; 14.5^{-}$ fold), an interesting molecule with antibacterial, antimycotic, antiviral, and anti-inflammatory activity, and secretory leukocyte protease inhibitor (SLPI; 5.3-fold), which antagonizes human neutrophil elastase, preventing tissue injury resulting from excessive proteolysis, in addition to possessing broad antimicrobial activity. In Slpi null mice increased leukocyte elastase levels lead to severely delayed wound healing with similarities to human chronic wound states [16].

In concordance with the pro-inflammatory aging state, not only is 'inflammatory response' the major GO group overrepresented in the list of genes up-regulated in delayed-healing wounds from elderly subjects (EASE $p=0.056$ ), but the endothelially expressed leukocyte adhesion mediator $S E L E$ displays the second highest fold-change (8.5-fold). SELE has previously been shown to be up-regulated in wounds from elderly mice and humans [17]. Moreover, Sele null mice display reduced local inflammation [18]. We also observed genes associated with regeneration up-regulated in delayed-healing wounds, including HOXC6 (embryonic skin patterning; 5.3fold) and TWIST1 (involved in liver regeneration; 4.5-fold) and in this regard it is intriguing that fetal-like regenerative cutaneous wound repair occurs in the elderly [2]. Insulin degradation in diabetic wounds has been associated with delayed healing [19] and insulin-degrading enzyme (IDE) is downregulated 20-fold in the aged and represented by multiple probe sets, suggesting that increased insulin may have no detrimental effect on wound healing in non-diabetics. Conversely, raised insulin levels have been postulated as a common link in promoting newt limb regeneration [20], which raises the possibility that this pathway is also involved in the reduced scarring phenotype observed in the elderly [2].

Many established wound healing genes are altered in wounds from elderly subjects and are estrogen regulated. Genes with attenuated expression include the classic pro-healing growth factor transforming growth factor alpha (TGFA; 8.5-fold down-regulated), genes linked to chronic wound healing, such as arginase 1 (ARG1; 82-fold down-regulated), and genes that when knocked out in mice delay healing, such as prostaglandin E receptor 3 (PTGER3; 7-fold down-regulated). Such a pronounced reduction in arginase (ARG1) expression in wounds from aged subjects is particularly interesting. L-arginine, an essential wound healing amino acid, is converted to nitric oxide, which acts to regulate inflammation. $A R G 1$ metabolizes L-arginine to generate proline, a substrate for collagen synthesis. Hence, $A R G 1$ is central to modulating the balance between inflammation and matrix deposition, an imbalance in which may explain the dramatic increase in inflammation and decrease in matrix deposition in the aged.

Aging-associated probe sets within our enriched data set were identified by interrogation of a publicly available handcurated database (the GenAge database) [12] to generate sub- 


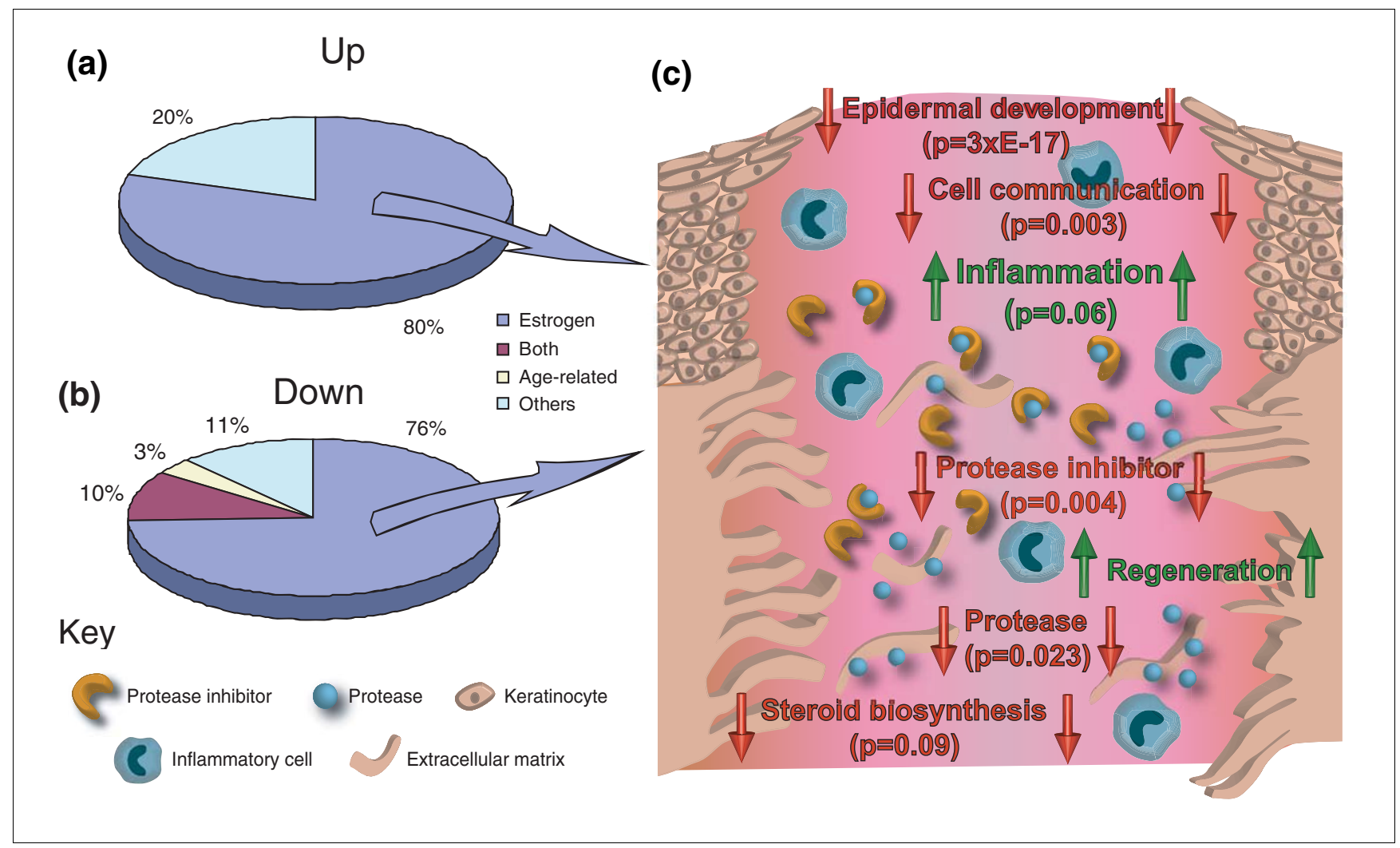

Figure 2

Estrogen-regulated wound-healing-associated genes predominate in age-associated delayed healing. (a,b) Graphical representation of the relative proportions of genes significantly up- (a) or down- (b) regulated in wounds from elderly subjects. (c) The key overrepresented GO groupings (functionally conserved gene groups) corresponding to each chart segment, their involvement in cutaneous healing, and significance of over-representation (EASE derived $p$-value). The majority of genes in our enriched data set (Additional data file I) are estrogen regulated and actively involved in cutaneous healing. Ontology groups in red are significantly overrepresented in genes down-regulated in wounds from elderly subjects while those in green are overrepresented in genes with increased expression in wounds from elderly subjects.

set $\mathrm{S} 4$ (Additional data file 6) or by annotation to known ageassociated processes (heat shock, mitochondria, neurodegeneration or response to UV GO groups or by hand annotation) to generate subset $\mathrm{S}_{5}$ (Additional data file 7). Table 2 shows differentially expressed aging-associated genes/probe sets identified in this study, all of which were down-regulated in wounds from elderly subjects. Only a single identified gene, HSPA8, is present in the GenAge human aging-related gene list (out of 243 human genes listed in GenAge; Additional data file 6). Moreover, not a single gene orthologue from the model organism GenAge list, which contains 571 genes that have been demonstrated to directly alter life-span in model organisms, is present in our enriched data set.

In light of the considerable overrepresentation of estrogenregulated genes identified in this study, we next asked whether there was statistically significant enrichment for ageassociated genes. Using a binomial distribution we calculate that, based on the size of the human GenAge database (243 genes), the total number of genes on the U133 array $(13,290)$ and the total number of genes in our data set (78), we would expect our enriched data set to contain 1.4 genes from the
GenAge database purely by chance. Hence we observe a surprising, non-statistically significant ( $p=0.72)$ under-representation of aging-associated genes. For this binomial calculation we have deliberately excluded the much larger list of GenAge genes shown to modulate lifespan in animal models, because of obvious orthologue issues. Including the full GenAge list gave a figure of 3.6 genes expected by chance $(p=$ o.16). Notably, HSPA8, the gene that we identified as being present in the GenAge database, is also estrogen-regulated. Indeed, $76 \%$ of the aging-related genes identified in this study were additionally estrogen-regulated. Hence, it follows that the most likely candidate genes for mediating intrinsic agingassociated effects on healing are directly estrogen-regulated. This observation underpins the key finding of this study, namely that estrogen-mediated changes in gene expression are central to age-associated delayed healing.

In an attempt to specifically identify further animal-model derived putative-human gerontogenes, we relaxed our array filtering criteria. Filtering for fold change $( \pm 1.5$-fold $), p$-value $(<0.05)$ and expression level $(>15)$ identified 20 genes from either the human or model organisms GenAge database 
Table 2

\begin{tabular}{|c|c|c|c|c|c|}
\hline Affy ID & Gene* & Gene (description) & Function & q-value ${ }^{\dagger}$ & $\mathrm{FC} \ddagger$ \\
\hline \multicolumn{6}{|c|}{ Down-regulated probe sets (12) } \\
\hline 217496_s_at & $I D E \S$ & insulin-degrading enzyme & $\begin{array}{l}\text { Wound fluid/resolution of insulin } \\
\text { response }\end{array}$ & 4.0E-06 & -20.5 \\
\hline 210074_at & CTSL2§ & cathepsin L2 & Lysosomal cysteine proteinase & $3.8 \mathrm{E}-05$ & -15.5 \\
\hline 2|4|3|_at & SERPINBI3 & $\begin{array}{l}\text { serpin peptidase inhibitor, clade B } \\
\text { (ovalbumin), member } 13\end{array}$ & UV-responsive proteinase inhibitor & I.IE-03 & -15.0 \\
\hline 21413|_at & CI2orf5 & $\begin{array}{l}\text { chromosome } 12 \text { open reading frame } \\
5\end{array}$ & Protection from DNA damage & I.IE-03 & -12.8 \\
\hline 204733_at & $K L K 6 \S$ & kallikrein 6 (neurosin, zyme) & Hormone regulated serine protease & I.4E-05 & -11.9 \\
\hline 202179_at & $B L M H^{\S}$ & bleomycin hydrolase & $\begin{array}{l}\text { Alzheimer's-associated cysteine } \\
\text { peptidase }\end{array}$ & 2.IE-03 & -11.8 \\
\hline 210338_s_at & HSPA8§ & heat shock $70 \mathrm{kDa}$ protein 8 & Aging-associated heat shock protein & $9.9 \mathrm{E}-04$ & -10.6 \\
\hline 201849_at & BNIP3§ & $\begin{array}{l}\text { BCL2/adenovirus EIB } 19 \mathrm{kDa} \\
\text { interacting protein } 3\end{array}$ & Mitochondrial apoptosis-inducing & 2.7E-04 & -10.1 \\
\hline 203328_x_at & $I D E \S$ & insulin-degrading enzyme & $\begin{array}{l}\text { Wound fluid/resolution of insulin } \\
\text { response }\end{array}$ & I.4E-05 & -17.4 \\
\hline 203327_at & IDE§ & insulin-degrading enzyme & $\begin{array}{l}\text { Wound fluid/resolution of insulin } \\
\text { response }\end{array}$ & 7.0E-04 & -9.3 \\
\hline 205016_at & TGFA§ & transforming growth factor, alpha & IFN-induced/epidermal regeneration & I.0E-03 & -8.5 \\
\hline 212907_at & SLC30AI & $\begin{array}{l}\text { Solute carrier family } 30 \text { (zinc } \\
\text { transporter), member I }\end{array}$ & Zinc/calcium ion transporter & 8.5E-04 & -7.3 \\
\hline
\end{tabular}

*Genes in bold have been validated by qPCR. †CyberT-derived multiple testing corrected q-value. \#Fold change (old/young). §Also estrogen-regulated (Table I).

(Additional data file 8). Again, this constituted under-representation, which in this instance was highly significant ( $p=$ o). Most noticeably we found that every identified putativelife span modulating gene (i.e., gerontogene) up-regulated in elderly human wounds acts to extend life-span in animal models (Additional data file 8). The observed beneficial effects of these genes in animal models are at odds with the detrimental nature of delayed human healing, again reinforcing the lack of importance of gerontogenes in the process. In contrast, while some down-regulated putative lifespan modulating genes (i.e., gerontogenes) were associated with extended lifespan (9 out of 14) others were associated with reduced lifespan (5 out of 14 ).

Those genes not regulated by estrogen nor classed as agingassociated (Table 3) were involved in diverse functions, such as energy supply and protein catabolism (20\% of up-regulated and $11 \%$ of down-regulated genes; Figure 2) or were of unknown function (36\% of genes) and could not, therefore, have been assigned to estrogen or age-associated gene lists.

In order to validate our data, primers were designed to 27 of the key genes identified in this study and quantitative realtime PCR (qPCR) carried out on the same wound samples as used for the arrays and on additional wound samples. In all cases the real-time findings confirmed the array results (Figure 3 and data not shown). We then examined the expression of these genes by qPCR in normal skin and wounds to deter- mine whether the observed changes were present prior to wounding or were specifically induced by wounding (Figure 4 and data not shown). Genes fell into two distinct groups segregating depending on estrogen-regulation or age-association. All estrogen-regulated genes displayed a statistically significant difference in expression between wounds from young and old subjects with a far lower magnitude difference in normal skin (Figure 4a; for example, $L O R$ ), indicating that the major effects of estrogen are on injured tissue. In contrast, all age-associated genes displayed pronounced change between old and young normal skin in addition to, and often of greater magnitude than, the wound (Figure $4 \mathrm{~b}$; for example, $S D H C$ ), suggesting that age-associated change precedes the healing response. Whilst this does not preclude such genes from influencing subsequent healing responses, our data suggest that not only does estrogen regulate the vast majority of genes involved in healing, but that the gene profiles mimic those seen in wounds from estrogen-deprived young animals (Figure 5a). Of 14 estrogen-regulated genes (selected from human subsets $\mathrm{S}_{1}, \mathrm{~S} 2$ and $\mathrm{S}_{3}$ ), 12 (86\%) were significantly changed in the same direction between human and mouse (Figure 5a). The remaining genes (PTPRO and $S P R R 1 A$ ) were also significantly changed in both human and mouse but in opposite directions. We next tested selected genes for direct estrogen regulation in vitro (Figure $5 \mathrm{~d}$ and data not shown). SELE, which is increased in both old human and ovx mouse wounds, was down-regulated by estrogen in vitro, while $L Y P D 3$ and $A R G 1$, decreased in both old human 
Table 3

\begin{tabular}{|c|c|c|c|c|c|}
\hline Affy ID & Gene & Gene (description) & Function & q-value* & $\mathrm{FC}+$ \\
\hline \multicolumn{6}{|c|}{ Downregulated probe sets $(10)$} \\
\hline 205000_at & $D D X 3 Y$ & $\begin{array}{l}\text { DEAD (Asp-Glu-Ala-Asp) box } \\
\text { polypeptide 3, Y-linked }\end{array}$ & $\begin{array}{l}\text { Male fertility-associated RNA } \\
\text { helicase }\end{array}$ & $5.9 \mathrm{E}-13$ & -78.6 \\
\hline 21752I_at & N54942 & Transcribed locus & Unknown & I.IE-05 & -20.1 \\
\hline 213780_at & $\mathrm{TCHH}$ & Trichohyalin & Hair follicle/cornified envelope & I.0E-02 & -13.8 \\
\hline 220322_at & ILIF9 & interleukin I family, member 9 & Keratinocyte cytokine & $9.7 \mathrm{E}-04$ & -9.9 \\
\hline 218454_at & FLJ22662 & hypothetical protein FLJ22662 & Unknown & I.2E-03 & -9.9 \\
\hline 218150_at & $A R L 5 A$ & ADP-ribosylation factor-like $5 \mathrm{~A}$ & $\begin{array}{l}\text { Developmentally regulated nuclear } \\
\text { protein }\end{array}$ & I.8E-03 & -9.0 \\
\hline 20500I_s_at & $D D X 3 Y$ & $\begin{array}{l}\text { DEAD (Asp-Glu-Ala-Asp) box } \\
\text { polypeptide 3, Y-linked }\end{array}$ & $\begin{array}{l}\text { Male fertility-associated RNA } \\
\text { helicase }\end{array}$ & I.IE-05 & -8.6 \\
\hline 21413|_at & CYorfI5B & $\begin{array}{l}\text { chromosome } Y \text { open reading frame } \\
\text { I5B }\end{array}$ & X-degenerate gene & I.IE-03 & -8.1 \\
\hline 203180_at & ALDHIA3 & $\begin{array}{l}\text { Aldehyde dehydrogenase I family, } \\
\text { member } \mathrm{A} 3\end{array}$ & Detoxification of aldehydes & 7.8E-03 & -8.0 \\
\hline 207602_at & TMPRSSIID & transmembrane protease, serine IID & Psoriasis-associated serine protease & 2.3E-04 & -7.9 \\
\hline \multicolumn{6}{|c|}{ Upregulated probe sets (2) } \\
\hline 213369_at & $\mathrm{PCDH} 2 \mathrm{I}$ & protocadherin 21 & Adhesion & I.3E-05 & 11.9 \\
\hline 221501_x_at & LOC339047 & hypothetical protein LOC339047 & Unknown & $9.8 \mathrm{E}-05$ & 9.3 \\
\hline
\end{tabular}

*CyberT-derived multiple testing corrected q-value. FFold change (old/young).

and ovx mouse wounds, was up-regulated by estrogen. Changes in gene expression were seen predominantly in macrophages reinforcing the role of inflammation in age-associated delayed healing.

Moreover, we reasoned that as both mouse groups (intact and ovx) were of equal age (ten weeks) then genes identified in human as age-associated should be unchanged upon mouse comparison. This was confirmed for $S L C 3 O A 1$, a gene identified as age-associated but not estrogen-regulated in human (Figure 5b; 1.o-fold), and an additional three genes identified in human as both age-associated and estrogen-regulated (Figure 5c; BNIP $3, H S P A 8$ and $I D E$ ). Wound expression of all three genes was not significantly altered between ovx and intact mice, indicating predominant association with age as opposed to estrogen status.

We next asked whether observed changes in gene expression translated into equivalent changes in wound protein levels. As epidermal genes were most significantly overrepresented in our enriched human data set we initially focussed on expression of key epidermal proteins (Figure 6). We selected the terminal differentiation markers loricrin (-235-fold gene expression) and involucrin (-8.8-fold gene expression), the desmosomal cadherin democollin1 (-28.9-fold gene expression) and the injury-associated intermediate filament protein keratin16 (-8.3-fold gene expression). In agreement with gene expression change, both loricrin and involucrin protein levels were reduced in suprabasal wound epidermis from elderly human subjects (Figure 6a-d). In addition, the estrogen-regulation was confirmed at the protein level by reduced expression of all four proteins in wound epidermis from ovx female mice compared to intact mice (Figure 6e-l). The difference in keratin 16 expression between intact and ovx mouse wounds was particularly striking (compare Figure 6e to $6 f$ ). We annotated keratin 16 as estrogen regulated (subset S3; Additional data file 4) based on its inclusion on the EstrArray custom estrogen-regulated gene microarray [21]. To our knowledge, this study provides the first demonstration of keratin 16 (KRT16) regulation by estrogen in vivo. Moreover, a pronounced lack of KRT16 in the wound edge epidermis from ovx mice is entirely novel and may represent an important contributing factor to delayed re-epithelialization, as keratin 16-mediated re-organization of intermediate filaments in wound edge keratinocytes has been proposed to facilitate re-epithelialization [22].

We then turned our attention to expression of proteins encoded by array-identified genes in cells within the granulation tissue of both human and mouse wounds (Figure 7). Protocadherin 21 (PCDH21), identified in this study as 12-fold up-regulated at the level of gene expression in wounds from elderly subjects, but belonging to neither age-associated nor estrogen-regulated subsets (Table 3), displayed statistically significant up-regulation in elderly wounds also at the protein level (Figure 7a,b). Notably, $P C D H 21$ has not previously been associated with wound healing, aging or estrogen-regulation. Serpin peptidase inhibitor, clade B (ovalbumin), member 13 


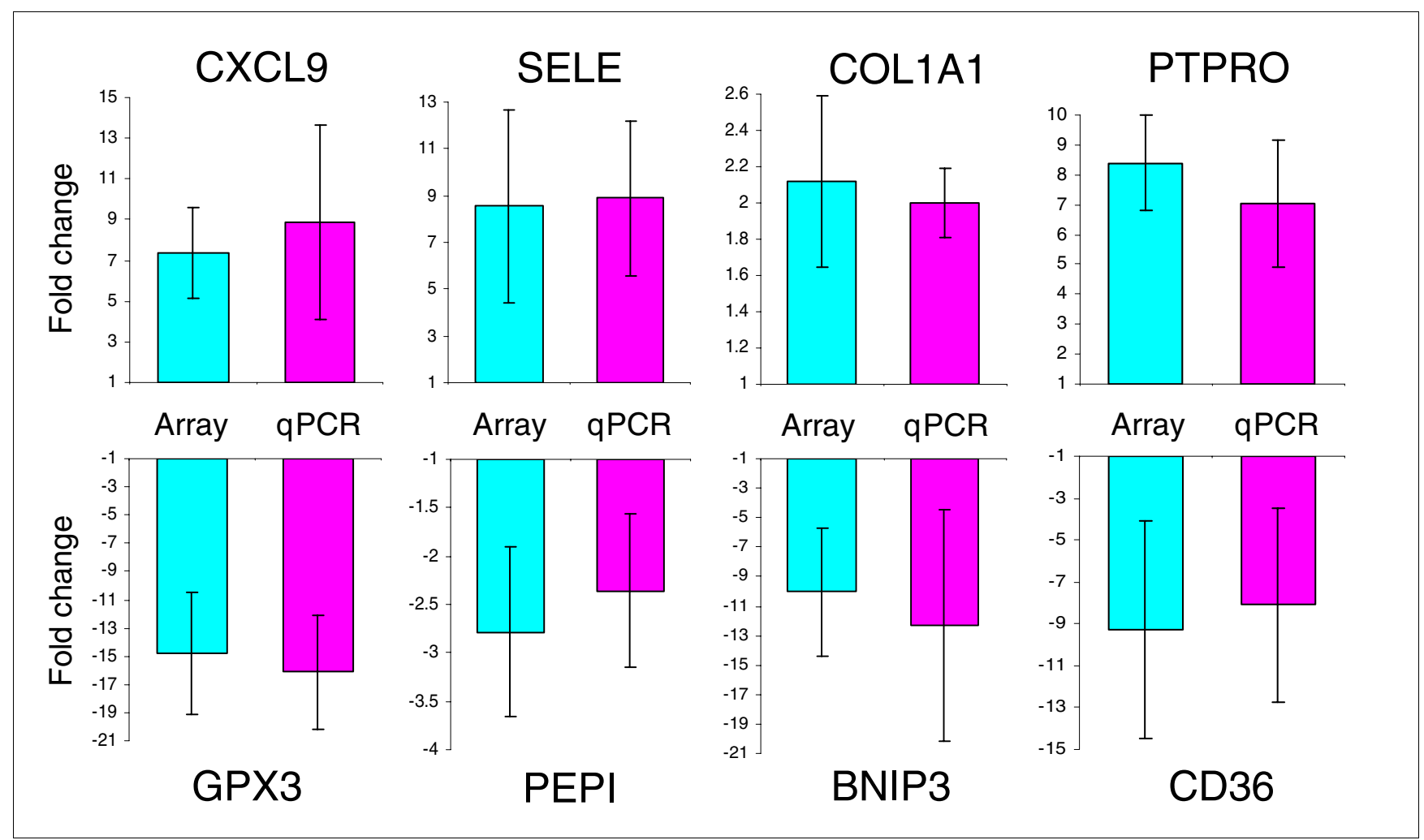

Figure 3

Validation of array-determined gene expression change by qPCR. Data are represented as fold change (old/young) for array data (blue) and qPCR data (pink). Results are presented as mean \pm standard error of the mean; $n=3$ for arrays and $n=5$ for QPCR.

(SERPINB13), identified in this study as age-associated but not estrogen regulated, and 15 -fold down-regulated in wounds from elderly subjects at the level of expression, was also reduced in elderly wounds at the protein level (Figure $7 \mathrm{c}, \mathrm{d})$.

Another estrogen-regulated gene with a potentially important role in healing is that encoding arginase 1 (ARG1; 82-fold down-regulated in wounds from elderly males). We find significantly less Arg1 expressing cells in the wound granulation tissue from ovx mice (Figure 7e,f). While Arg1 is known to be estrogen regulated in uterus and prostate, it has not previously been shown to be estrogen regulated in skin. Again, this novel finding may be important in light of the role of arginase in modulating the balance between inflammation and matrix deposition during healing, and in the progression of chronic wounds [23]. Finally, we returned to Serpinb13 (a gene identified in this study in human as age-associated but not estrogen-regulated) and determined protein levels in wounds from ovx and intact young female mice. Immunohistochemical analysis demonstrated that the number of cells expressing Serpinb13 protein was unaltered by estrogen status in young female mice (Figure $7 \mathrm{~g}, \mathrm{~h}$ ), validating this gene as age-associated but not estrogen-regulated.

\section{Conclusion}

Our data clearly implicate estrogen, and not candidate gerontogenes nor 'age-associated' genes, as the most potent regulator of age-associated delay in human wound healing, a discovery underscored by the numerous associations between estrogen-regulated gene polymorphisms and phenotypes representing aging phenomena, including wound healing $[24,25]$. Whilst expression changes in a few genes that appear to be specifically associated with chronological age were noted, the majority of these genes were indeed also estrogen regulated. It is likely, in fact, that there is an intimate relationship between hormones and aging. Recent reports suggest that the model organism Caenorhabditis elegans contains several hormonal steroids that can increase lifespan by up to $20 \%$, and that the insulin growth factor/insulin pathway influences the rate of aging $[26,27]$. That regulation by estrogen at the level of the gene appears to be the most important mediator of age-related delayed wound healing suggests that post-transcriptional aging phenomena such as free radical damage, glycation, and protein error do not play a major role in this process. We suggest that tissue repair acts as a paradigm for the effects of estrogen on other age-related pathophysiological processes, linking estrogen-regulated genes directly to a protective repair/maintenance program and thus abating 'aging'. 


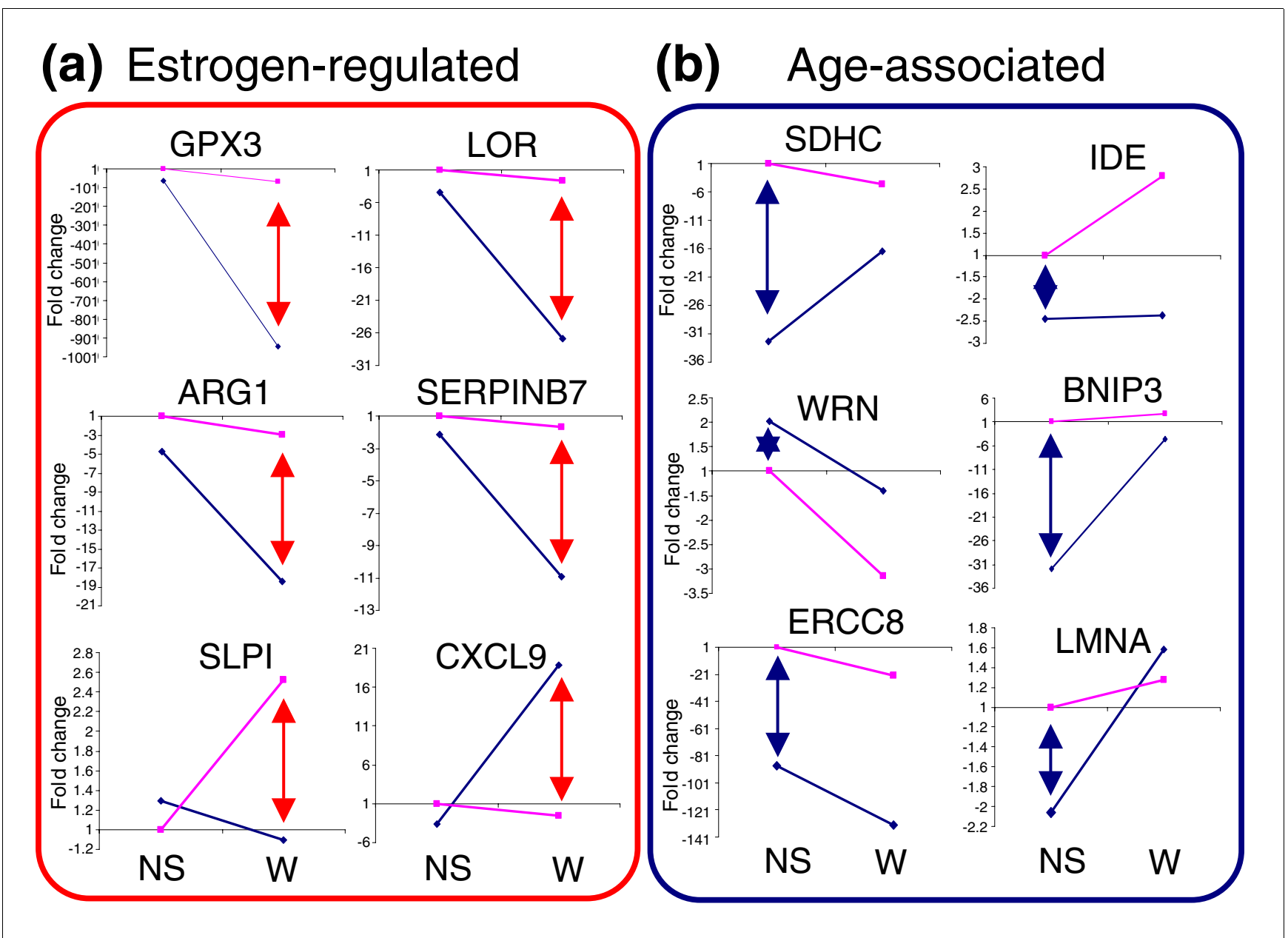

Figure 4

Quantification of gene expression change by qPCR. Comparison of gene expression between normal skin (NS) and wounds (W) from young (pink) and old (blue) human subjects. (a) All estrogen-regulated genes tested displayed clear differential wound expression (red double-ended arrow) with more parity of expression in normal skin. (b) In contrast, genes identified as age-associated displayed pronounced changes in normal skin (blue double-ended arrow) of similar or greater magnitude than the wound gene expression change. $n=3-5$ per group.

\section{Materials and methods}

\section{Sample collection and histology}

Local ethical committee approval was obtained for all human studies. Following informed consent eighteen healthy, young males and nineteen health status-defined elderly males underwent two $4 \mathrm{~mm}$ punch biopsies from the left upper inner arm after local infiltration with $1 \mathrm{ml}$ of $1 \%$ lignocaine. The first biopsy (normal skin) was followed by re-biopsy of the same site at one of four pre-defined time points to excise wound tissue. The selected time points were three days, seven days, three months and six months post-initial biopsy. Tenweek-old female $\mathrm{C}_{57} / \mathrm{Bl} 6$ mice with intact ovaries and tenweek-old $\mathrm{C}_{57} / \mathrm{Bl6}$ mice that had undergone ovariectomy one month previously were anesthetized and wounded following our established protocol [9] (in accordance with home office regulations). Briefly, two equidistant $1 \mathrm{~cm}$ full-thickness skin incisional wounds were made through both skin and panniculus carnosus muscle, and left to heal by secondary intention. Wounds were excised and bisected at day 3 after wounding, with one-half of the sample processed for histology.

Histological sections were prepared from biopsy/mouse wound tissue fixed in $10 \%$ buffered formalin and embedded in paraffin. Sections $(5 \mu \mathrm{m})$ were stained with hematoxylin and eosin, or subjected to immunohistochemistry with mouse monoclonal anti-CD15 (BD Biosciences, Pharmingen, Oxford, UK), mouse monoclonal anti-CD68, anti-VWF (Dako, Cambridge, UK), anti-MIF goat polyclonal antibody (R\&D Systems, Abingdon, UK), anti-LOR, anti-INV (Covance, Berkeley, CA, USA), JCMC (rabbit polyclonal antiDsc1), anti-K16, anti-ARG1 (Santa Cruz Biotechnology, Santa Cruz, CA, USA), anti-PCDH21 or anti-SERPINB13 (Abcam, Cambridge, UK) and the appropriate biotinylated secondary antibody followed by ABC-peroxidase reagent (Vector Laboratories, Peterborough, UK) with Novared substrate and 


\section{(a)

\begin{tabular}{|c|c|c|}
\hline \multicolumn{2}{|c|}{ Dragon (Subset S1) } & $\begin{array}{l}\text { Mouse } \\
\text { 1) }\end{array}$ \\
\hline-14.5 & LTF & -2.3 \\
\hline-8.8 & DEFB4 & -3.2 \\
\hline-6.1 & ARG1 & -1.9 \\
\hline 7.0 & PTPRO & -3.0 \\
\hline \multicolumn{3}{|c|}{ Mouse data set (Subset S2) } \\
\hline-19.9 & HOP & -7.4 \\
\hline-9.7 & LYPD3 & -1.9 \\
\hline-8.1 & CD36 & -3.7 \\
\hline & SPRR1A & 2.3 \\
\hline \multicolumn{3}{|c|}{ Hand annotated (Subset S3) } \\
\hline-58.9 & HAL & -2.3 \\
\hline-10.5 & SERPINB3 & -6.2 \\
\hline-6.5 & SERPINB7 & -1.9 \\
\hline-3.5 & DSC1 & -2.3 \\
\hline 47.9 & CXCL9 & 3.3 \\
\hline $2.5 \angle$ & SELE & \\
\hline
\end{tabular}

(b) Age-associated

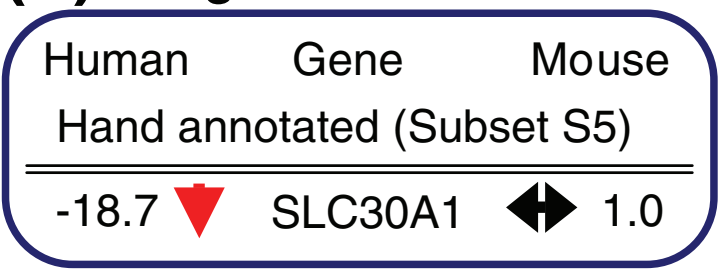

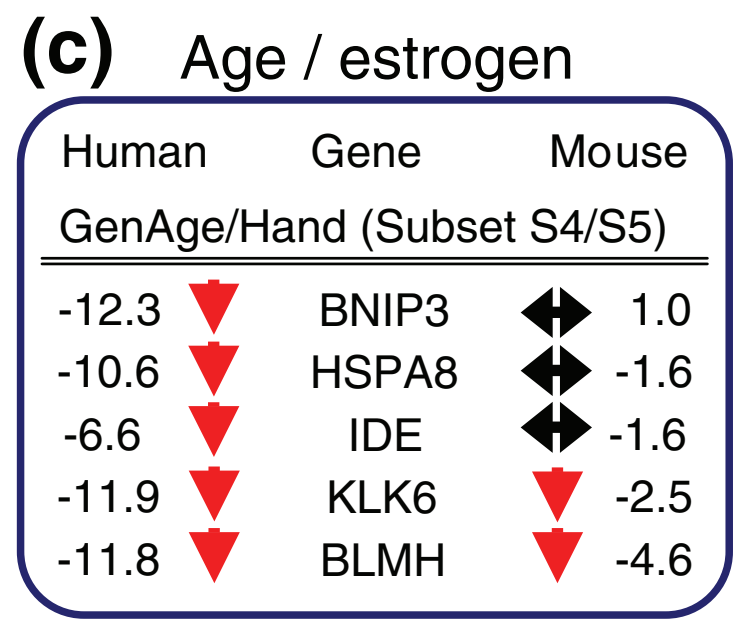

(d)
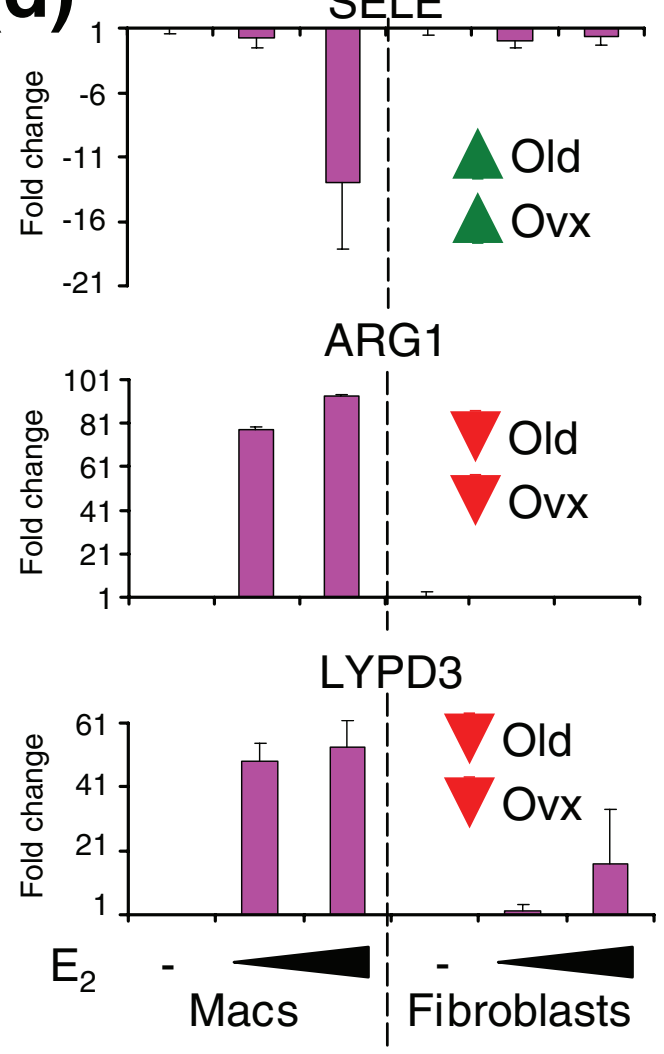

Figure 5

Gene expression changes identified in aged males are mirrored in ovx female mice. $(\mathbf{a}, \mathbf{b})$ Comparison of wound gene expression change between human males (old/young; left) and estrogen-deprived young female mice (ovx/intact; right). Arrows indicate direction of change, green up and red down. (a) Estrogen-regulated genes are similarly changed in both mouse and human. (b) In contrast, a gene identified as age-associated is unchanged in wounds from ovx female mice. (c) Genes categorized as both estrogen-regulated and age-associated were either unchanged in mouse (indicating predominant ageassociation) or similarly changed in both mouse and human (indicating predominant estrogen-regulation). (d) Demonstration that selected array-identified genes are directly estrogen regulated in mouse primary macrophages and/or fibroblasts in vitro. Results are presented as mean \pm standard error of the mean; $n=3-6$ per group. 


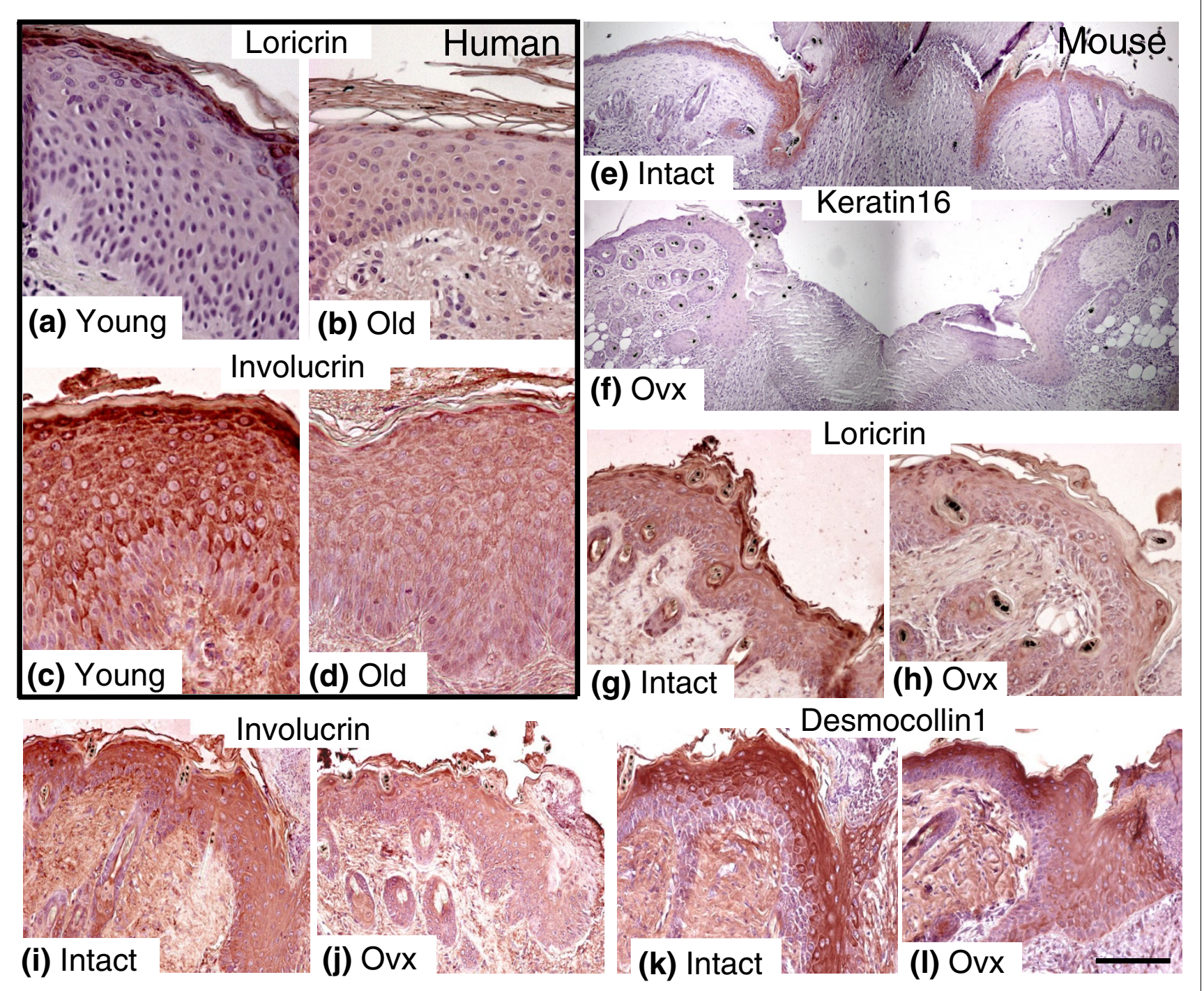

\section{Figure 6}

Immunohistochemical analysis of epidermal proteins encoded by array-identified estrogen-regulated genes demonstrates altered expression in wounds from both old humans and ovx young female mice. (a-d) Representative immunohistochemical localization of the epidermal differentiation markers loricrin and involucrin demonstrates decreased expression in wound epidermis from old males compared to wounds from young males. (e-l) Representative immunohistochemical localization of the epidermal proteins keratin 16, loricrin, involucrin and desmocollin I, which are decreased in wound epidermis from young ovx mice compared to wounds from mice with intact ovaries. The scale bar in (I) represents $70 \mu \mathrm{m}(\mathrm{a}-\mathrm{d}), 300 \mu \mathrm{m}$ (e-f), and $140 \mu \mathrm{m}(\mathrm{g}-\mathrm{j})$.

counterstaining with hematoxylin. Control slides stained with secondary antibody in isolation or control IgG were negative. Total cell numbers and re-epithelialization were quantified with Image Pro Plus software as previously described [8] (MediaCybernetics, Silver Spring, MD, USA).

\section{Sample collection and RNA preparation}

Following informed consent, five healthy, young males (2427 years old) and five health status-defined elderly males (7176 years old) underwent two $4 \mathrm{~mm}$ punch biopsies from the left upper inner arm after local infiltration with $1 \mathrm{ml}$ of $1 \%$ lignocaine. The first biopsy (normal skin) was followed by re- biopsy of the same site seven days later to excise wound tissue. In addition, ten-week-old female BALB/c mice with intact ovaries and ten-week-old mice that had undergone ovariectomy one month previously were anesthetized and wounded following our established protocol [9] (in accordance with home office regulations). Wounds were excised and bisected three days after wounding, and one-half of the wound was flash frozen at $-80^{\circ} \mathrm{C}$ before RNA extraction. Total RNA was isolated from frozen tissue by homogenizing in Trizol reagent (Invitrogen, Paisley, UK) following the manufacturer's instructions. 
(a)

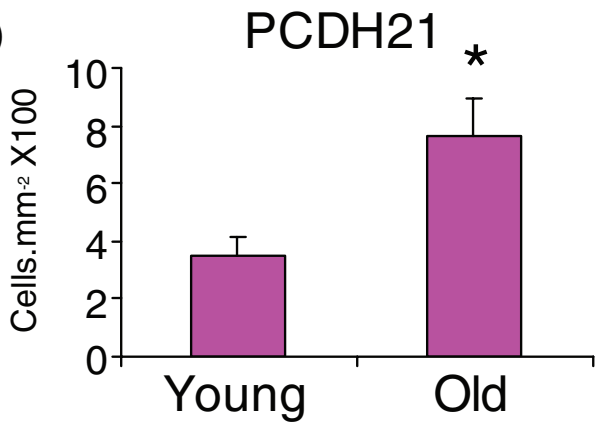

(c)

(e)
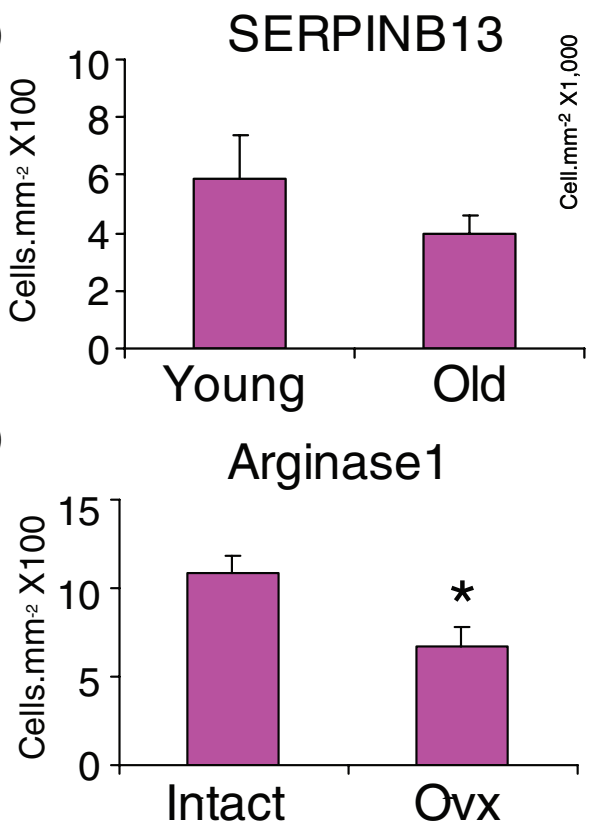

(g)

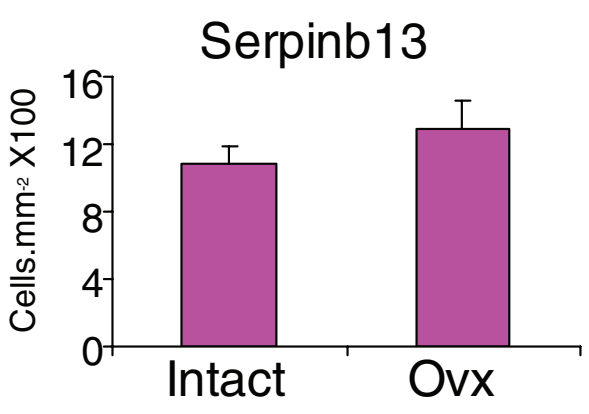

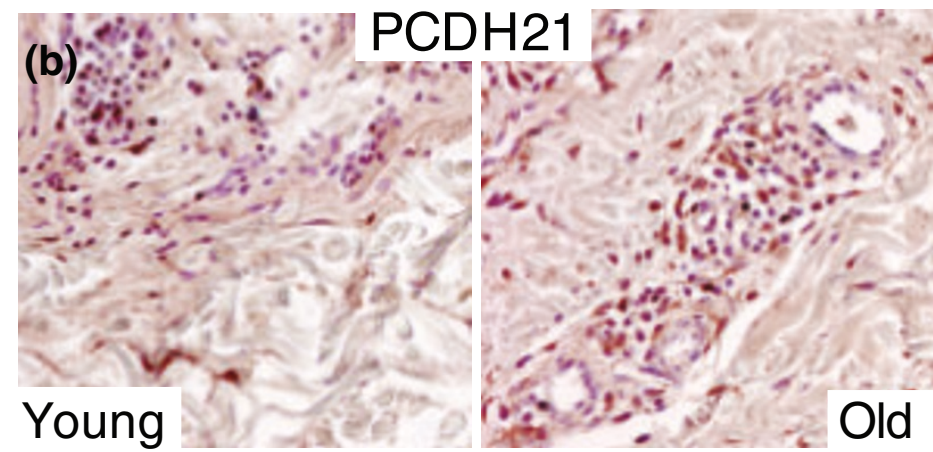
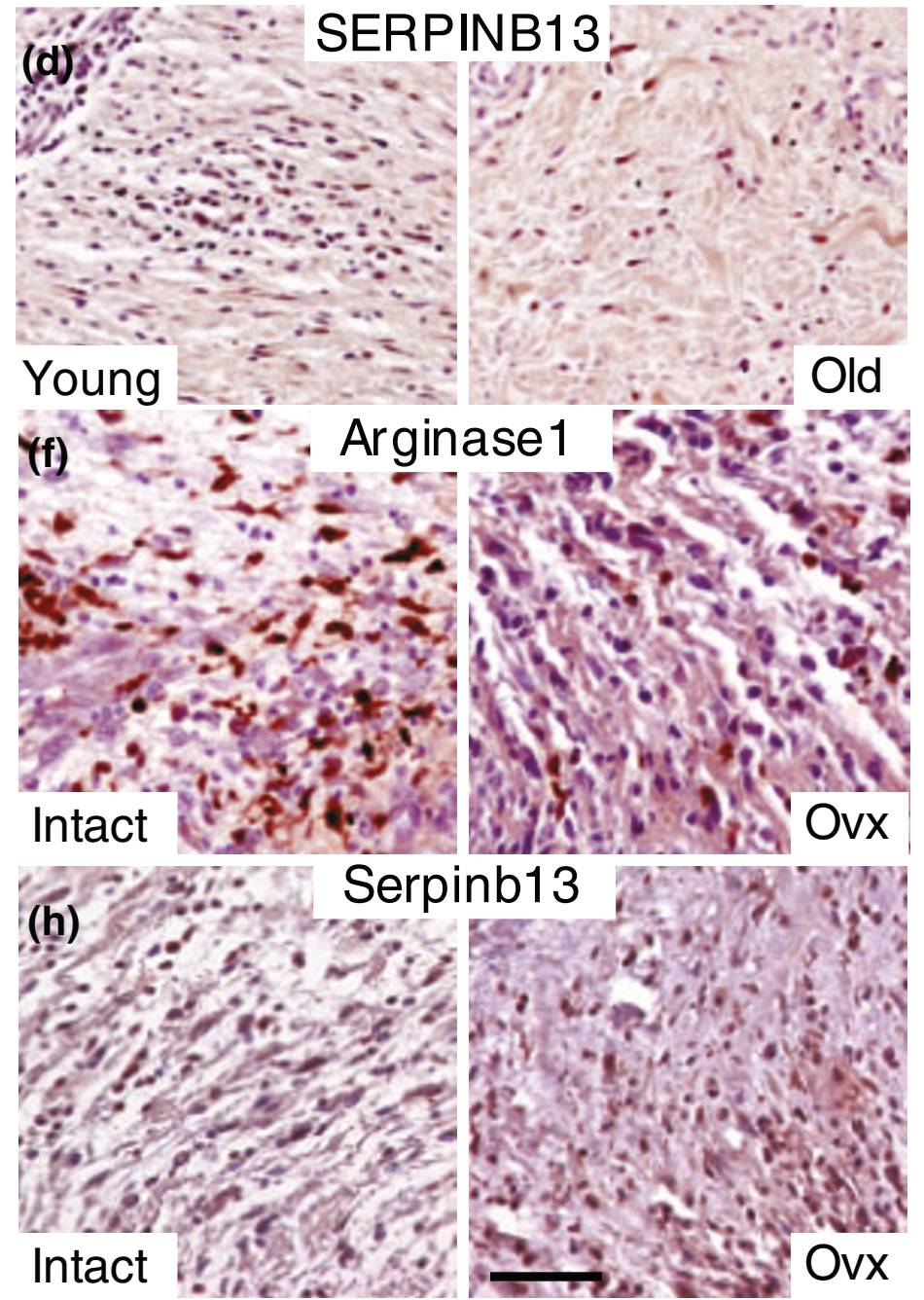

Figure 7

Immunohistochemical analysis of proteins encoded by array-identified dermally expressed genes during human and murine wound healing. (a-d) In agreement with array findings, human wound granulation tissue protein levels of Protocadherin 2I (a) and SERPINBI 3 protein (b) mirrors changes in gene expression. $(\mathbf{e}, \mathbf{f})$ In mice, the number of granulation tissue cells expressing arginase $I$ is reduced in wounds from ovx mice, mirroring the human array findings and validating this gene/protein as estrogen regulated. $(\mathbf{g}, \mathbf{h})$ In contrast, yet also in agreement with human array findings, the number of granulation tissue cells expressing serpinb 13 was not significantly altered between intact and ovx mice, that is, not dependent on estrogen levels. Results are presented as mean \pm standard error of the mean; $* p<0.05$. The scale bar in (h) represents $45 \mu \mathrm{m}(\mathrm{b}, \mathrm{d}), 20 \mu \mathrm{m}(\mathrm{f})$ and $35 \mu \mathrm{m}(\mathrm{h}) ; \mathrm{n}=3-6$ per group. 


\section{Cell culture}

Mouse peritoneal macrophages were isolated by intraperitoneal lavage with ice-cold sterile phosphate-buffered saline, pooled for subsequent studies and cell viability determined by trypan blue. Cells were re-suspended at a concentration of $10^{6}$ cells per $\mathrm{ml}$ in serum-free phenol-red free Dulbecco's modified Eagle's medium (DMEM) medium, treated with lipopolysaccharide $(1 \mathrm{mg} / \mathrm{ml})$ and $10^{-7}$ or $10^{-8} \mathrm{M} 17-\beta$-estradiol (Sigma-Aldrich, St Louis, MO, USA) or lipopolysaccharide alone. Cells were washed, $0.5 \mathrm{ml}$ TRIzol (Invitrogen Corp., Carlsbad, CA, USA) was added per well, and plates were stored at $-80^{\circ} \mathrm{C}$ before RNA extraction. Mouse dermal fibroblasts were isolated as follows. Epidermis and dermis were separated following overnight incubation in $0.25 \%$ Trypsin/ EDTA (Cascade Biologics, Portland, OR, USA) at $4^{\circ} \mathrm{C}$. Minced dermis was incubated in $0.3 \%$ collagenase in DMEM for 30 minutes at $37^{\circ} \mathrm{C}$ in $5 \% \mathrm{CO}_{2}$ atmosphere with regular agitation. The collagenase-cell mixture was filtered, centrifuged, and isolated fibroblasts washed with fresh media (DMEM, 5\% fetal calf serum, L-glutamine, 1\% Penicillin, Streptomycin, and Amphotericin B (PSA) prior to plating. Cells were plated and cultured until confluent in DMEM medium supplemented with Penicillin/Streptomycin and 10\% charcoalstripped fetal calf serum (Thermo Scientific, Waltham, MA, USA). Confluent fibroblasts were treated with lipopolysaccharide $\left(1 \mathrm{mg} / \mathrm{ml}\right.$ ) and $10^{-8}$ or $10^{-9} \mathrm{M} 17-\beta$-estradiol (SigmaAldrich) or lipopolysaccharide alone. Cells were washed, 0.5 ml TRIzol (Invitrogen Corp.) was added per well, and plates were stored at $-80^{\circ} \mathrm{C}$ before RNA extraction.

\section{Microarray analysis}

Human microarray experiments were performed using the human genome U133A oligonucleotide array (Affymetrix Inc., High Wycombe, UK) according to the manufacturer's instructions. Total wound RNA (100 ng) from three old and three young male subjects was used with the Two-Cycle cDNA Synthesis Kit (P/N 900432 Affymetrix Inc.; one sample hybridized per array). Technical quality control was performed with dChip [28]. Background correction, quantile normalization, and gene expression analysis were performed using GCRMA [29]. The microarray data were submitted in MIAME (minimum information about a microarray experiment)-compliant format to the ArrayExpress database [30]. Differential expression between the young and old groups was tested statistically with CyberT on logarithmic scale data [31]. False-discovery correction was performed with Q-value software [32]. Significantly changed probe sets were selected on fold change ( \pm 7 -fold), q-value $(<0.1)$ and expression level (>15) (see Additional data file 1 for a full list). For up- and down-regulated gene data sets overrepresented GO groups were identified using the second generation (DAVID 2007) expression analysis systematic explorer (EASE) online functional annotation tool [33] (Additional data file 5). Mouse microarray experiments were performed as previously described [9], ArrayExpress database accession number emexp-209. Briefly, biotinylated cRNA samples from individual intact and ovx mice were hybridized to mouse 430A oligonucleotide arrays (Affymetrix Inc., Santa Clara, CA, USA). For this current experiment data were re-analyzed using GCRMA for background correction, quantile normalization, and gene expression analysis [29]. Differential expression between the intact and ovx groups was tested statistically with CyberT on logarithmic scale data [31]. Significantly changed probe sets were selected on fold change ( \pm 1.5 -fold), $p$-value $(<0.1)$ and expression level (>50).

Hormonally regulated genes were identified by: comparison of significantly changed human probesets (Additional data file 1) with the Dragon online database of estrogen regulated genes [11] to generate conserved gene subset S1 (Additional data file 2); cross-species comparison of human genes identified in this study (U133A microarrays) with genes up- or down-regulated in hormonally mediated delayed-healing murine wounds (430A microarrays) to generate conserved gene subset S2 (Additional data file 3); and hand annotation as estrogen-regulated following an exhaustive literature search to generate conserved gene subset $S_{3}$ (Additional data file 4). Aging-associated genes were identified using: comparison of significantly changed human probesets (Additional data file 1) with the hand curated GenAge database of agingassociated genes [12] to generate conserved gene subset $\mathrm{S}_{4}$ (Additional data file 6); combined with genes annotated with known age-associated ontology groups (DNA damage, mitochondria, neurodegeneration or response to UV) and/or hand annotated as age-associated following an exhaustive literature search to generate conserved gene subset $\mathrm{S}_{5}$ (Additional data file 7 ).

\section{qPCR and comparison with microarrays}

cDNA was transcribed from $0.5 \mu \mathrm{g}$ of human wound RNA (five old and five young male subjects), from $0.5 \mu \mathrm{g}$ of human normal skin RNA (three old and three young subjects), from $1 \mu \mathrm{g}$ of mouse wound RNA (six intact and six oxv mice) and 1 $\mu \mathrm{g}$ of RNA isolated from estrogen-treated macrophages or fibrolasts. (Promega RT kit and AMV-reverse transcriptase; Roche, Welwyn Garden City, UK). Primer sequences were designed to each gene coding sequence independently of the Affymetrix probe set target region sequence and hence may or may not be directed to the same gene region. qPCR was performed using the SYBR green core kit (Eurogentec, Southampton, UK) following the manufacturer's instructions and an Opticon qPCR thermal cycler (Bio-Rad, Hemel Hempstead, UK). For each primer set an optimal dilution was determined, and melting curves were used to determine product specificity. Each sample was serially diluted over three orders of magnitude, and for each primer set all samples were run on the same 96-well plate. For primer sequences see Additional data file 9. Expression ratios were determined relative to a standard sample and normalized using a value derived from three separate control primer sets to $18 \mathrm{~s}$ rRNA and the housekeeping genes Gapdh and Ywahz. In Figure 4, fold change is presented relative to young normal skin with 
values below 1 converted to negative fold change. In Figure 5, data for estrogen treated cells is presented as fold change relative to each cell type treated with lipopolysaccharide alone with values below 1 again converted to negative fold change.

\section{Data deposition}

Microarray data have been deposited in MIAME compliant format in the ArrayExpress database [34], accession number E-MEXP-1074.

\section{Abbreviations}

DMEM, Dulbecco's modified Eagle's medium; EASE, expression analysis systematic explorer; GO, gene ontology; MIAME, minimum information about a microarray experiment; ovx, ovariectomised; qPCR, quantitative realtime PCR.

\section{Authors' contributions}

MJH was involved in study design, carried out experiments and data analysis, and was involved in manuscript preparation. GSA was involved in study design and manuscript preparation. Both MJH and GSA have had full access to all of the data in the study and take responsibility for the integrity of the data and the accuracy of the data analysis.

\section{Additional data files}

The following additional data are available. Additional data file 1 is a table listing all probe sets identified as differentially expressed using the filtering criteria fold change ( \pm 7 -fold), qvalue (<0.1) and expression level (>15). Additional data file 2 is a table listing the full subset $\mathrm{S} 1$ - Dragon database-derived estrogen-regulated probe sets. Additional data file 3 is a table listing the full subset $\mathrm{S} 2$ - mouse dataset-derived estrogenregulated probe sets. Additional data file 4 is a table listing the full subset $\mathrm{S}_{3}$ - hand-annotated estrogen-regulated probe sets. Additional data file 5 is a table listing the full EASE experimental readout. Additional data file 6 is a table listing the full subset $\mathrm{S}_{4}$ - GenAge-derived aging-associated probe sets. Additional data file 7 is a table listing the full subset $\mathrm{S}_{5}$ hand-curated and aging-associated GO probe sets. Additional data file 8 is a table listing differentially expressed genes identified in this study, using a relaxed array filtering criteria, that have also been demonstrated to alter life-span in animal models. Additional data file 9 is a table listing all primers used for qPCR.

\section{Acknowledgements}

We thank A Hayes, L Zeef and L Wardleworth from the University of Manchester Core Microarray Facility. This work was supported by the Wellcome Trust and Research Into Ageing who played no role in any decisions relating to the data nor paper. The authors declare no conflict of interest.

\section{References}

I. Holliday R: Aging is no longer an unsolved problem in biology. Ann NY Acad Sci 2006, 1067: 1-9.

2. Ashcroft GS, Dodsworth J, van Boxtel E, Tarnuzzer RW, Horan MA, Schultz GS, Ferguson MW: Estrogen accelerates cutaneous wound healing associated with an increase in TGF-betal levels. Nat Med 1997, 3:1209-1215.

3. Ashcroft GS, Greenwell-Wild T, Horan MA, Wahl SM, Ferguson MW: Topical estrogen accelerates cutaneous wound healing in aged humans associated with an altered inflammatory response. Am J Pathol 1999, I55: I |37- I I 46.

4. Taylor RJ, Taylor AD, Smyth JV: Using an artificial neural network to predict healing times and risk factors for venous leg ulcers. J Wound Care 2002, I I:I0I-105.

5. Malay DS, Margolis DJ, Hoffstad OJ, Bellamy S: The incidence and risks of failure to heal after lower extremity amputation for the treatment of diabetic neuropathic foot ulcer. J Foot Ankle Surg 2006, 45:366-374.

6. Ashcroft GS, Mills SJ: Androgen receptor-mediated inhibition of cutaneous wound healing. J Clin Invest 2002, I I 0:6 I 5-624.

7. Warner HR: Longevity genes: from primitive organisms to humans. Mech Ageing Dev 2005, I 26:235-242.

8. Ashcroft GS, Mills SJ, Ashworth J]: Ageing and wound healing. Biogerontology 2002, 3:337-345.

9. Hardman MJ, Waite A, Zeef L, Burow M, Nakayama T, Ashcroft GS: Macrophage migration inhibitory factor: a central regulator of wound healing. Am J Pathol 2005, 167:|56|-1574.

10. Piatetsky-Shapiro G, Tamayo P: Microarray data mining: facing the challenges. SIGKDD Explorations 2003, 5:I-5.

II. Tang S, Han H, Bajic VB: ERGDB: Estrogen Responsive Genes Database. Nucleic Acids Res 2004, 32(Database issue):D533-D536.

12. de Magalhães JP, Costa J, Toussaint O: HAGR: the Human Ageing Genomic Resources. Nucleic Acids Res 2005, 33(Database issue):D537-D543.

13. Xia YP, Zhao Y, Tyrone JW, Chen A, Mustoe TA: Differential activation of migration by hypoxia in keratinocytes isolated from donors of increasing age: implication for chronic wounds in the elderly. J Invest Dermatol 200 I, I I 6:50-56.

14. Holt DR, Kirk SJ, Regan MC, Hurson M, Lindblad WJ, Barbul A: Effect of age on wound healing in healthy human beings. Surgery 1992, I I 2:293-297.

15. Miyata $T$, Inagi $R$, Nangaku $M$, Imasawa $T$, Sato $M$, Izuhara $Y$, Suzuki D, Yoshino A, Onogi H, Kimura M, Sugiyama S, Kurokawa K: Overexpression of the serpin megsin induces progressive mesangial cell proliferation and expansion. I Clin Invest 2002, 109:585-593.

16. Ashcroft GS, Lei K, Jin W, Longenecker G, Kulkarni AB, GreenwellWild T, Hale-Donze H, McGrady G, Song XY, Wahl SM: Secretory leukocyte protease inhibitor mediates non-redundant functions necessary for normal wound healing. Nat Med 2000, 6:1147-II53.

17. Ashcroft GS, Horan MA, Ferguson MW: Aging alters the inflammatory and endothelial cell adhesion molecule profiles during human cutaneous wound healing. Lab Invest 1998, 78:47-58.

18. Labow MA, Norton CR, Rumberger JM, Lombard-Gillooly KM, Shuster DJ, Hubbard J, Bertko R, Knaack PA, Terry RW, Harbison ML, Kontgen F, Stewart CL, McIntyre KW, Will PC, Burns DK, Wolitzky BA: Characterization of E-selectin-deficient mice: demonstration of overlapping function of the endothelial selectins. Immunity 1994, I:709-720.

19. Duckworth WC, Fawcett J, Reddy S, Page JC: Insulin-degrading activity in wound fluid. J Clin Endocrinol Metab 2004, 89:847-85I.

20. Vethamany-Globus S: Hormone action in newt limb regeneration: insulin and endorphins. Biochem Cell Biol 1987, 65:730-738

2I. Terasaka S, Aita Y, Inoue A, Hayashi S, Nishigaki M, Aoyagi K, Sasak $\mathrm{H}$, Wada-Kiyama Y, Sakuma Y, Akaba S, Tanaka J, Sone H, Yonemoto J, Tanji M, Kiyama R: Using a customized DNA microarray for expression profiling of the estrogen-responsive genes to evaluate estrogen activity among natural estrogens and industrial chemicals. Environ Health Perspect 2004, I I 2:773-78I.

22. Paladini RD, Takahashi K, Bravo NS, Coulombe PA: Onset of re-epithelialization after skin injury correlates with a reorganization of keratin filaments in wound edge keratinocytes: defining a potential role for keratin 16. J Cell Biol 1996, 
| 32:38|-397.

23. Abd-El-Aleem SA, Ferguson MW, Appleton I, Kairsingh S, Jude EB, Jones K, McCollum CN, Ireland GW: Expression of nitric oxide synthase isoforms and arginase in normal human skin and chronic venous leg ulcers. J Pathol 2000, I 9 I:434-442.

24. Ashworth JJ, Smyth JV, Pendleton N, Horan M, Payton A, Worthington J, Ollier WE, Ashcroft GS: The dinucleotide (CA) repeat polymorphism of estrogen receptor beta but not the dinucleotide (TA) repeat polymorphism of estrogen receptor alpha is associated with venous ulceration. I Steroid Biochem Mol Biol 2005, 97:266-270.

25. Ashworth J], Smyth JV, Pendleton N, Horan M, Payton A, Worthington J, Ollier WE, Ashcroft GS: Polymorphisms spanning the $\mathbf{O N}$ exon and promoter of the estrogen receptor-beta (ERbeta) gene ESR2 are associated with venous ulceration. Clin Genet 2008, 73:55-6I.

26. Broué F, Liere P, Kenyon C, Baulieu EE: A steroid hormone that extends the lifespan of Caenorhabditis elegans. Aging Cell 2007, 6:87-94.

27. Murphy CT, McCarroll SA, Bargmann Cl, Fraser A, Kamath RS, Ahringer J, Li H, Kenyon C: Genes that act downstream of DAF I 6 to influence the lifespan of Caenorhabditis elegans. Nature 2003, 424:277-283.

28. Li C, Wong WH: Model-based analysis of oligonucleotide arrays: expression index computation and outlier detection. Proc Natl Acad Sci USA 200I, 98:3I-36.

29. Wu Z, Irizarry RA, Gentleman R, Murillo FM, Spencer F: A modelbased background adjustment for oligonucleotide expression arrays. Working Papers, Department of Biostatistics, Johns Hopkins University 2004 [http://www.bepress.com/jhubiostat/paper I].

30. MIAME workgroup [http://www.mged.org/Workgroups/MIAME/ miame.html]

31. Baldi P, Long AD: A Bayesian framework for the analysis of microarray expression data: regularized t-test and statistical inferences of gene changes. Bioinformatics 2001, I 7:509-519.

32. Storey JD, Tibshirani R: Statistical significance for genomewide studies. Proc Natl Acad Sci USA 2003, I 00:9440-9445.

33. Hosack DA, Dennis G Jr, Sherman BT, Lane HC, Lempicki RA: Identifying biological themes within lists of genes with EASE. Genome Biol 2003, 4:R70.

34. ArrayExpress [http://www.ebi.ac.uk/arrayexpress] 